\title{
Exploring the Sensitivity of Photosynthesis and Stomatal Resistance Parameters in a Land Surface Model ${ }^{\circ}$
}

\author{
JENNIFER L. JEFFERSON ${ }^{\mathrm{a}}$ \\ Hydrologic Science and Engineering Program, and Department of Geology and Geological Engineering, Colorado \\ School of Mines, Golden, Colorado \\ REED M. MAXWELL \\ Hydrologic Science and Engineering Program, and Department of Geology and Geological Engineering, and \\ Integrated Groundwater Modeling Center, Colorado School of Mines, Golden, Colorado \\ PAul G. CONSTANTINE \\ Department of Applied Mathematics and Statistics, Colorado School of Mines, Golden, Colorado
}

(Manuscript received 4 March 2016, in final form 31 October 2016)

\begin{abstract}
Land surface models, like the Common Land Model component of the ParFlow integrated hydrologic model (PF-CLM), are used to estimate transpiration from vegetated surfaces. Transpiration rates quantify how much water moves from the subsurface through the plant and into the atmosphere. This rate is controlled by the stomatal resistance term in land surface models. The Ball-Berry stomatal resistance parameterization relies, in part, on the rate of photosynthesis, and together these equations require the specification of 20 input parameters. Here, the active subspace method is applied to 2100 year-long PF-CLM simulations, forced by atmospheric data from California, Colorado, and Oklahoma, to identify which input parameters are important and how they relate to three quantities of interest: transpiration, stomatal resistance from the sunlit portion of the canopy, and stomatal resistance from the shaded portion. The slope $(\mathrm{mp})$ and intercept (bp) parameters associated with the Ball-Berry parameterization are consistently important for all locations, along with five parameters associated with ribulose bisphosphate carboxylase/oxygenase (RuBisCO)- and light-limited rates of photosynthesis $\left[\mathrm{CO}_{2}\right.$ Michaelis-Menten constant at $25^{\circ} \mathrm{C}(\mathrm{kc} 25)$, maximum ratio of oxygenation to carboxylation (ocr), quantum efficiency at $25^{\circ} \mathrm{C}$ (qe25), maximum rate of carboxylation at $25^{\circ} \mathrm{C}(\mathrm{vcmx} 25)$, and multiplier in the denominator of the equation used to compute the light-limited rate of photosynthesis (wj1)]. The importance of these input parameters, quantified by the active variable weight, and the relationship between the input parameters and quantities of interest vary seasonally and diurnally. Input parameter values influence transpiration rates most during midday, summertime hours when fluxes are large. This research informs model users about which photosynthesis and stomatal resistance parameters should be more carefully selected. Quantifying sensitivities associated with the stomatal resistance term is necessary to better understand transpiration estimates from land surface models.
\end{abstract}

Supplemental information related to this paper is available at the Journals Online website: http://dx.doi.org/10.1175/ JHM-D-16-0053.s1.

\footnotetext{
${ }^{\text {a }}$ Current affiliation: Wisconsin Department of Natural Resources, Madison, Winconsin.
}

Corresponding author e-mail: Jennifer L. Jefferson, jennifer. jefferson@wisconsin.gov

\section{Introduction}

Recent developments in satellite technology allow us to see snapshots of vegetation coverage across the entire world (Zhang et al. 2006; NASA 2015). Physically, the vegetation that we can see in these images is moving water from the subsurface and into the atmosphere via transpiration: water is taken up by roots, continues up the plant structure, and escapes into the atmosphere when leaf stomata open to facilitate carbon uptake for photosynthesis. 
Hydrologic models, including land surface and groundwater models, are commonly used to understand how water and energy are distributed between the subsurface, land surface, and atmosphere. Land surface models use parameterizations to represent physical processes like transpiration, and they require several input parameters to characterize the vegetation. Transpiration also depends on the availability of water in the root zone and atmospheric conditions, but the physiological details are condensed into one term in land surface models - the stomatal resistance. The parameterization and calculation of this particular term becomes especially important when considering uncertainties associated with modeled estimates of transpiration and latent heat.

Several stomatal resistance parameterizations exist (Damour et al. 2010; Leuning et al. 1995; Jarvis 1976), but the Ball-Berry approach (Collatz et al. 1991) is widely used in land surface models like the Common Land Model (CLM). The Ball-Berry parameterization is an empirical formulation that relies, in part, on the rate of photosynthesis, which can be limited by light, the rate of carboxylation, or the export of products out of the reaction center (Collatz et al. 1991). Together, the stomatal resistance and photosynthesis equations require the selection or specification of at least 20 parameters. These values are typically hard coded within the land surface model, which makes them difficult to update, and have limited documentation regarding their assigned values. Furthermore, it is common for parameters like the slope and intercept terms of the Ball-Berry equation and the maximum rate of carboxylation to hold the same value for all vegetation types, even though they have been shown to vary (Kattge et al. 2009). Databases and research regarding photosynthesis parameters exist within the plant community (e.g., Kattge et al. 2009; Wullschleger 1993; Gu et al. 2010), but their extension to land surface model parameters is limited.

The stomatal resistance is used to compute the rate of transpiration. Transpiration can be a significant portion of the latent heat energy flux when vegetation has access to sufficient amounts of water and energy (Lawrence et al. 2007; Schlaepfer et al. 2014). However, most land surface model sensitivity analyses that evaluate latent heat (e.g., Bastidas et al. 1999; Henderson-Sellers 1993; Rosero et al. 2010; Li et al. 2013; Liang and Guo 2003; Liu et al. 2004; Göhler et al. 2013) do not consider transpiration explicitly; they include few, if any, stomatal resistance or photosynthesis parameters. For example, in a sensitivity analysis using an 18-day period of atmospheric forcing from the Great Plains, only two out of the 32 parameters considered were associated with physiologic controls. One of those two parameters (temperature adjustment to the maximum carboxylation rate) was found to be important for latent heat estimates (Liu et al. 2004). Using a longer analysis period, $\mathrm{Li}$ et al. (2013) completed approximately 400 one-year CLM simulations using a domain and atmospheric forcing representative of a watershed in China. Of the 40 parameters evaluated, two stomatal resistance parameters and two photosynthesis parameters were included; one of the photosynthesis parameters (quantum efficiency) was consistently important for latent heat estimates (Li et al. 2013). Another sensitivity analysis using CLM was completed by Göhler et al. (2013), where approximately 3000 two-year simulations were completed for deciduous and evergreen vegetation types located in France. Göhler et al. (2013) considered 66 parameters, five of which were associated with plant physiology, and found that photosynthesis estimates were sensitive to two plant parameters: maximum rate of carboxylation and the Ball-Berry stomatal resistance slope parameter. Realizing that parameter sensitivities might vary in time, Prihodko et al. (2008) used the Simple Biosphere Model, version 2 (SiB2; Sellers et al. 1996), to evaluate how sensitivities associated with 32 soil and 14 vegetation parameters varied by month at a forested site in northern Wisconsin. After conducting 20000 simulations, approximately 10 photosynthesis parameters were identified as highly influential during the summer season and neighboring months. These studies indicate that estimates of transpiration, and therefore latent heat, can be sensitive to parameters associated with the stomatal resistance formulation.

A variety of sensitivity analysis methods have been used to evaluate land surface models (Jefferson et al. 2015; Beringer et al. 2002). While individual sensitivity methods vary in their mathematical approaches, the overall goal is the same: to understand the relationship between model inputs and outputs. The active subspace method (Constantine 2015) is relatively new to the field of hydrology (Jefferson et al. 2015; Gilbert et al. 2016) but has been previously used in engineering applications (Constantine et al. 2014; Lukaczyk et al. 2014). Information obtained from the use of this method includes 1) the relative importance of each selected input parameter, quantified through the active variable weight, and 2) a low-dimensional model, visualized through a sufficient summary plot, which represents the relationship between the model's inputs and the output quantity of interest. Specifically, the low-dimensional model reveals how perturbations of important input parameters strongly impact output quantity estimates. The combination of the active variable weights and sufficient summary plot can be used to gain insight into model behavior in a way that other sensitivity methods cannot.

In this paper, we conduct a sensitivity analysis using the active subspace method to identify which Ball-Berry stomatal resistance and photosynthesis parameters most strongly influence three quantities of interest: transpiration, stomatal resistance from the sunlit portion of the canopy, and stomatal resistance from the shaded portion 
of the canopy. Of the few studies that evaluate sensitivities associated with the transpiration portion of the latent heat flux, most do not include a comprehensive list of parameters used to compute the stomatal resistance. The model domains used in previous studies are also location specific and it is unclear whether parameters identified as important at one site can be extended to another. Here, we use the CLM, coupled to the ParFlow (PF) integrated hydrologic model, to model single-column domains with deciduous tree cover. We apply atmospheric forcing from three different climates in an attempt to control for the effect that location has on parameter sensitivities. Furthermore, because transpiration rates vary seasonally and diurnally, we hypothesize that parameter sensitivities will also vary in time. The research questions we address in this manuscript include the following:

1) Do important stomatal resistance and photosynthesis parameters depend on atmospheric conditions associated with different geographic locations?

2) Which stomatal resistance and photosynthesis parameters exert the most control on transpiration and stomatal resistance estimates?

3) How do sensitivities vary seasonally (i.e., by month) and diurnally (i.e., by hour)?

The results provide insight to the behavior of modeled transpiration and stomatal resistance estimates and allow us to make recommendations on how careful the modeler should be when specifying model parameters.

\section{Methods}

\section{a. Transpiration in PF-CLM}

The Common Land Model is composed of a series of land surface modules that are called as a subroutine within the ParFlow integrated groundwater model to compute energy and water fluxes into and out of the land surface. Soil evaporation and transpiration fluxes remove water from the soil column. These fluxes are incorporated into the Richards equation so that soil pressures can be solved for by ParFlow (Kollet and Maxwell 2008; Atchley and Maxwell 2011; Ferguson et al. 2016). Transpiration $E_{\mathrm{tr}}\left(\mathrm{kg} \mathrm{m}^{-2} \mathrm{~s}^{-1}\right)$ occurs from the dry portion of the canopy $L_{d}$ (unitless):

$$
\begin{aligned}
E_{\mathrm{tr}}= & {\left[\frac{L_{d} r_{b}}{L_{\mathrm{AI}}}\left(\frac{L_{\mathrm{AI}, \text { sun }}}{r_{b}+r_{s, \text { sun }}}+\frac{L_{\mathrm{AI}, \text { sha }}}{r_{b}+r_{s, \text { sha }}}\right)\right] } \\
& \times \rho_{a} \frac{\left(L_{\mathrm{AI}}+S_{\mathrm{AI}}\right)}{r_{b}}\left(q_{f}-q_{c}\right),
\end{aligned}
$$

where the potential transpiration [i.e., the terms in (1) following the square brackets] depends on the air density $\rho_{a}\left(\mathrm{~kg} \mathrm{~m}^{-3}\right)$, leaf area index $L_{\mathrm{AI}}$ (unitless), stem area index $S_{\mathrm{AI}}$ (unitless), boundary layer resistance factor $r_{b}\left(\mathrm{~s} \mathrm{~m}^{-1}\right)$, and the humidity gradient between the foliage $q_{f}$ (unitless) and canopy air $q_{c}$ (unitless). Leaf and stem area index values are specified by plant functional type (PFT) and vary throughout the year, but there is only one canopy layer (i.e., no multilayer capability) and only one PFT is allowed per tile (i.e., no fractional vegetation). The dry portion of the canopy is partitioned into sunlit (sun) and shaded (sha) fractions, each with separate photosynthetically active radiation (PAR), $L_{\mathrm{AI}}$, and stomatal resistance $r_{s}\left(\mu \mathrm{mol} \mathrm{m}{ }^{-2} \mathrm{~s}^{-1}\right)$ values. All variables in (1), along with PAR, are updated at each model time step.

Daytime $r_{s}$ is parameterized using the Ball-Berry approach:

$$
\frac{1}{r_{s}}=m \frac{A}{c_{s}} \frac{e_{s}}{e_{i}} P_{\mathrm{atm}}+b
$$

where $A$ is the rate of photosynthesis $\left(\mu \mathrm{mol} \mathrm{CO}_{2} \mathrm{~m}^{-2} \mathrm{~s}^{-1}\right)$, $c_{s}(\mathrm{~Pa})$ is the $\mathrm{CO}_{2}$ concentration at the leaf surface, and $P_{\text {atm }}(\mathrm{Pa})$ is the atmospheric pressure. Together, the saturated vapor pressure at the vegetation temperature $e_{s}$ $(\mathrm{Pa})$ and the vapor pressure of the canopy air $e_{i}(\mathrm{~Pa})$ combine to form the relative humidity. Two parameters are used to relate $r_{s}$ to the rate of photosynthesis, $\mathrm{CO}_{2}$ concentration, and pressures: a slope parameter $m$ (unitless) and the minimum stomatal resistance $b\left(\mu \mathrm{mol} \mathrm{m}^{-2} \mathrm{~s}^{-1}\right)$. During daytime hours in PF-CLM (i.e., PAR $>0$ ) the rate of photosynthesis is limited by one of three mechanisms: the ribulose bisphosphate carboxylase/oxygenase (RuBisCO) enzyme $w_{c}$, the buildup of products from the photosynthesis reaction $w_{e}$, or the amount of light $w_{j}$. The photosynthesis rate is used to compute $c_{s}$ so that the quadratic equation can be used to solve (2) for $r_{s}$. Both $w_{c}$ and $w_{j}$ depend on the internal $\mathrm{CO}_{2}$ concentration of the leaf $c_{i}$, which is solved for iteratively using $A, c_{s}$, and $r_{s}$. At night, when PAR $\leq 0$, the stomatal resistance is set to a constant value:

$$
r_{s}=\min \left\{\begin{array}{l}
r_{s, \max } \\
b\left(\mathrm{~s} \mathrm{~m}^{-1}\right)
\end{array}\right.
$$

where $r_{s, \max }\left(\mathrm{s} \mathrm{m}^{-1}\right)$ is the maximum stomatal resistance. $^{1}$

\footnotetext{
${ }^{1}$ To convert (between $\mu \mathrm{mol} \mathrm{m}^{-2} \mathrm{~s}^{-1}$ and $\mathrm{s} \mathrm{m}^{-1}$ ), multiply or divide by the conversion factor $\left(\mathrm{cf} ; \mu \mathrm{mol} \mathrm{m}^{-3}\right)$ : $\mathrm{cf}=$ $\left(P_{\mathrm{atm}} 10^{6}\right) /\left[8.314\left(t_{a}+0.0098 h_{t}\right)\right]$, where $10^{6}$ is a conversion factor (from mol to $\mu \mathrm{mol}$ ), $8.314 \mathrm{~Pa} \mathrm{~m}^{3} \mathrm{~K}^{-1} \mathrm{~mol}^{-1}$ is the gas constant, $t_{a}(\mathrm{~K})$ is the air temperature, $0.0098 \mathrm{~K} \mathrm{~m}^{-1}$ is the adiabatic lapse rate, and $h_{t}$ $(2 \mathrm{~m})$ is the height at which the air temperature is measured.
} 


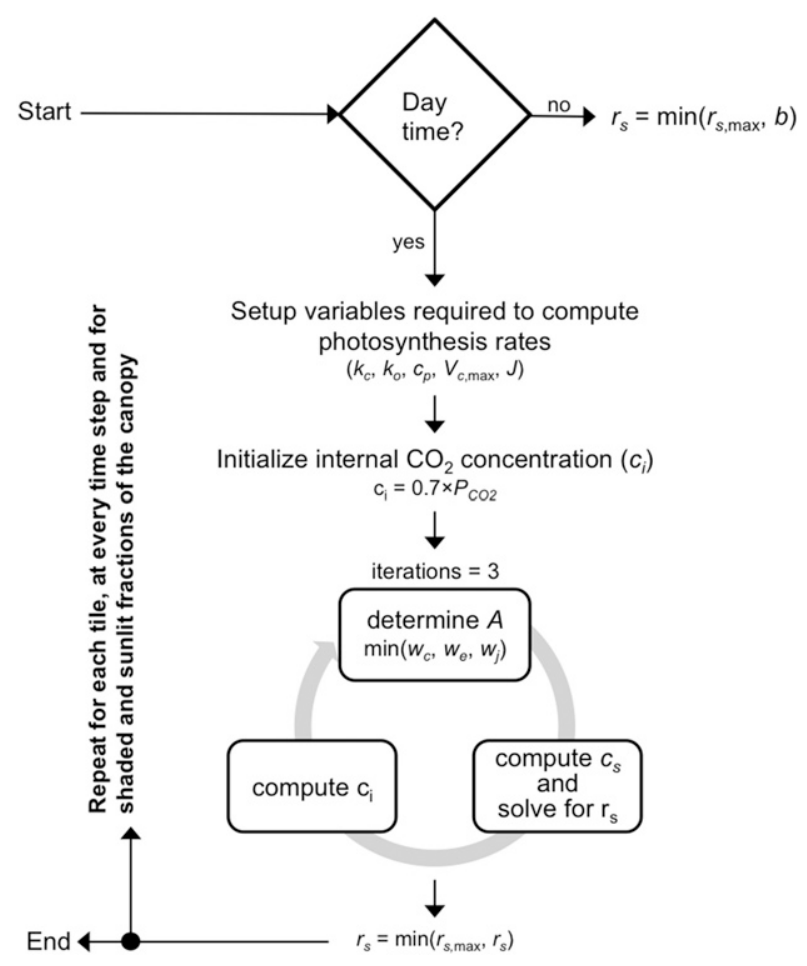

FIG. 1. Flowchart of stomatal resistance computation in PFCLM. See appendix for additional photosynthesis variables and equations.

Figure 1 shows a flowchart of the $r_{s}$ computation, which is completed for each PF-CLM tile, at every time step, for both the sunlit and shaded fractions of the dry canopy. This series of calculations is repeated three times before $r_{s}$ is inserted into (1) to estimate the transpiration flux. Collectively, the stomatal resistance (2) and the photosynthesis equations (appendix) require that 20 different parameter values be specified (Table 1); this is nearly the same number of parameters required to characterize vegetation properties (Jefferson et al. 2015). Some of the stomatal resistance and photosynthesis parameters can be obtained or estimated from physical measurements (e.g., $V_{c, \max }$, $x_{\mathrm{CO}_{2}}, m$, and $\left.b\right)$. However, information about most of these parameter values is limited. The default values in Table 1 are constant for all times and vegetation types in PF-CLM. Several of these parameters are hard coded within the module while others are assigned during the subroutine initialization. If users want to change any of these parameter values, they must locate them within the source code files, make the desired changes, and recompile the code.

\section{b. PF-CLM setup and datasets}

All PF-CLM simulations completed as part of this research used a $2 \mathrm{~m} \times 2 \mathrm{~m} \times 10 \mathrm{~m}$ deep single-column domain. To control for the effect of geographic location on stomatal resistance and photosynthesis parameter sensitivities, the land cover and subsurface were specified as deciduous vegetation and loam soil (hydraulic conductivity $=0.04465 \mathrm{~m} \mathrm{~h}^{-1}$, porosity $=0.512$, van Genuchten $\alpha=4.0738 \mathrm{~m}^{-1}$, and van Genuchten $n=2.19$; where $\alpha$ and $n$ are parameters estimated from soil-water retention data with differing values for different types of soil), respectively. Hourly atmospheric forcing datasets from three locations were considered: 1 year from Breckenridge, Colorado (Mikkelson et al. 2013); 1 year from the Little Washita watershed in Oklahoma (Kollet and Maxwell 2008); and 3 years (average, wet, and dry) from the Tonzi Ranch field site in California (Gou 2014). Table 2 summarizes precipitation totals, average air temperature, and average incoming shortwave radiation for the five atmospheric forcing datasets. The Colorado and Oklahoma sites receive precipitation throughout the year, whereas precipitation at the California site primarily occurs between December and May, with little to no precipitation in the summer months. Air temperatures are similar at the Oklahoma and California sites and coolest at the snow-dominated Colorado site. All locations are in the Northern Hemisphere and receive greater amounts of shortwave radiation in the summer. Forcing from each location was iteratively applied to the single-column domain until the subsurface storage reached a steady state. This resulted in initial water-table depths of $0.4,1.1$, and $1.2 \mathrm{~m}$ for the Colorado, Oklahoma, and California simulations, respectively.

Two additional single-column scenarios were completed to incorporate site-specific information from the Little Washita watershed. These simulations were forced with the Oklahoma atmospheric dataset described above. The first set of additional simulations kept deciduous tree as the land cover, but used soil properties (loamy sand) and a deeper water table $(8 \mathrm{~m})$ to more accurately describe actual subsurface conditions (Condon and Maxwell 2014; Kollet and Maxwell 2008). Since most of the land cover in the Little Washita watershed is grassland (Condon and Maxwell 2014), the second set of additional simulations included updated soil, water-table, and land surface properties.

Many quantities are output from PF-CLM, but this research focused on three: the rate of transpiration, the stomatal resistance of the sunlit portion of the canopy, and the stomatal resistance of the shaded portion of the canopy. To assess whether parameter sensitivities vary with time, daytime hourly outputs for each of these three quantities were averaged by month for the entire year and by hour for the summer months of June-August.

\section{c. Active subspaces for sensitivity analysis}

The active subspace method was used to evaluate the sensitivity of monthly- and hourly-averaged rates of 


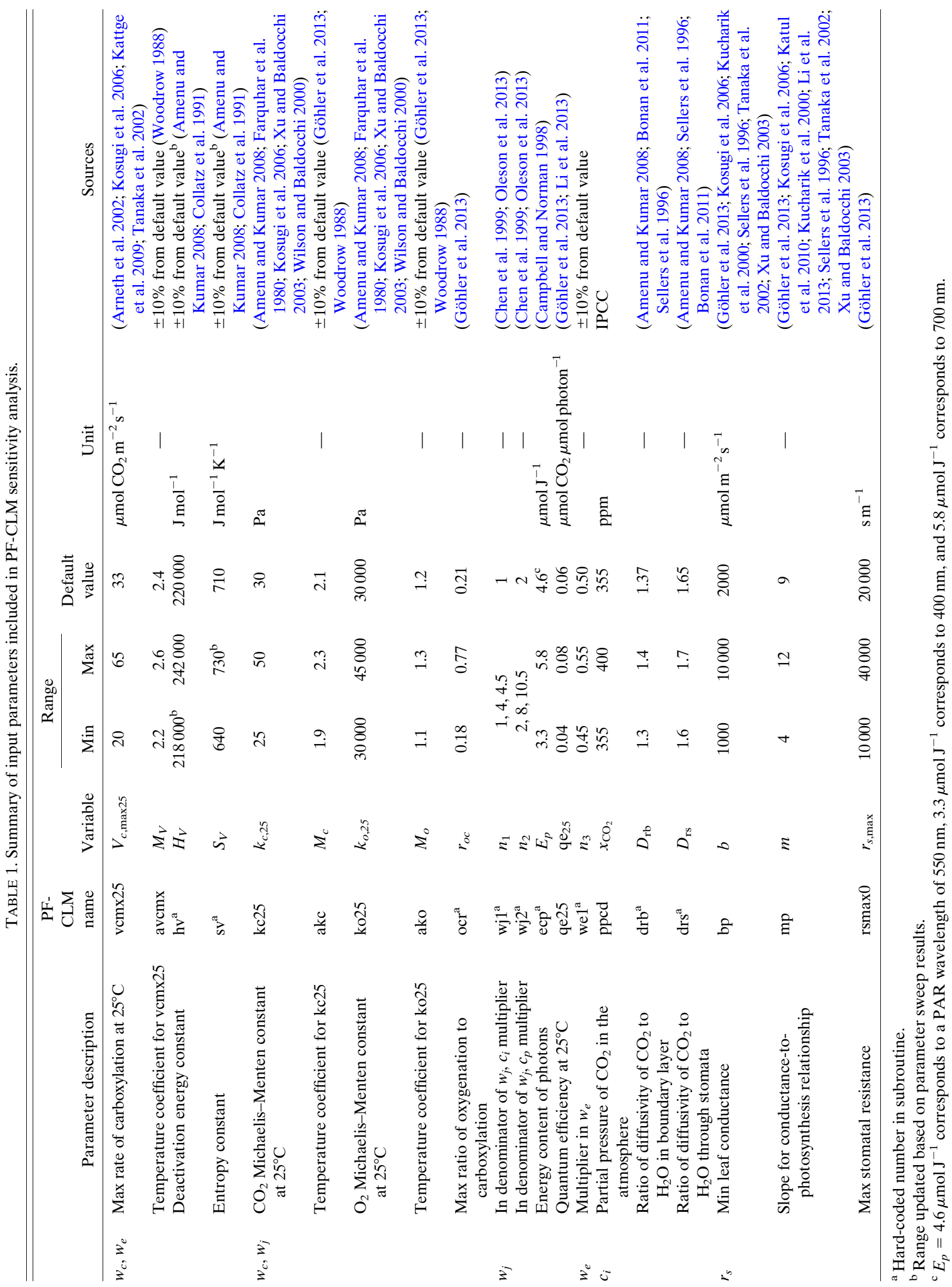


TABLE 2. Summary of meteorological forcing data for each site.

\begin{tabular}{|c|c|c|c|c|c|}
\hline & \multirow[b]{2}{*}{ Colorado (2007-08) } & \multirow[b]{2}{*}{ Oklahoma (1998-99) } & \multicolumn{3}{|c|}{ California } \\
\hline & & & $2002-03$ & $2005-06$ & $2007-08$ \\
\hline \multicolumn{6}{|l|}{ Total precipitation (mm) } \\
\hline Annual & 615.8 & 955.9 & 581.9 & 887.4 & 394.2 \\
\hline September-November & 75.7 & 232.8 & 63.2 & 38.3 & 58.9 \\
\hline December-May & 381.4 & 480.1 & 501.7 & 849.1 & 334.8 \\
\hline June-August & 158.7 & 243.0 & 17.0 & 0.0 & 0.5 \\
\hline \multicolumn{6}{|l|}{ Avg air temperature $(\mathrm{K})$} \\
\hline Annual & 270.9 & 290.6 & 289.4 & 289.5 & 289.1 \\
\hline June-August & 282.1 & 301.3 & 296.9 & 297.8 & 297.3 \\
\hline \multicolumn{6}{|c|}{ Avg shortwave radiation $\left(\mathrm{W} \mathrm{m}^{-2}\right)$} \\
\hline Annual & 200.0 & 243.6 & 205.5 & 207.5 & 213.8 \\
\hline June-August & 263.0 & 324.8 & 318.4 & 326.4 & 320.0 \\
\hline
\end{tabular}

transpiration and stomatal resistance to the parameters shown in Table 1 . The active subspace method is a gradient-based global sensitivity approach that identifies the directions in the input parameter space along which perturbations most strongly influence selected output quantities. Because gradients of each input parameter with respect to the desired output quantity of interest are not available from PF-CLM, they are approximated using a linear model of the output as a function of the inputs [see algorithm 1.3 in Constantine (2015)]. We applied this algorithm using the following four steps:

1) Sample 300 sets of 20 stomatal resistance and photosynthesis parameters input parameter values from the uniform distributions specified in Table 1. Complete a PF-CLM simulation with each set of input parameter values. A total of 2100 year-long PF-CLM simulations were completed $\left[\approx 8760 \mathrm{~h} \mathrm{yr}^{-1} \times\right.$ 300 realizations $\times(5$ forcing sets +2 additional scenarios) $\approx 18$ million $\mathrm{h}$ of output data].

2) Compute quantities of interest from PF-CLM output data: transpiration rates, sunlit stomatal resistance, and shaded stomatal resistance.

3) Use least squares to fit coefficients of a linear model using pairs of quantities of interest and input parameter values. Use the coefficients to compute the active variable weight (i.e., the normalized gradient of the linear model) for each quantity of interest (see Fig. 2, left).

4) Compute the active variable for each realization by adding up the product of each normalized input value and active variable weight. Make a sufficient summary plot where the active variable is on the $x$ axis and the corresponding quantity of interest value is on the $y$ axis (see Fig. 2, right). Each point on the sufficient summary plot corresponds to one realization (i.e., one model run).
This sensitivity approach is closely related to techniques for sufficient dimension reduction in statistical regression models (Cook 1998). A sufficient summary plot that shows a near-univariate relationship confirms that the linear model identified a single important direction in the 20-dimensional input parameter space. The plot also visualizes the input-output relationship. A thorough explanation of the active subspaces method, as well as its derivation and prior applications in hydrology, can be found in Constantine (2015), Gilbert et al. (2016), and Jefferson et al. (2015).

The active subspace method produces a set of weights-one for each input parameter for each quantity of interest. These weights quantify the relative importance of each parameter; they are computed independently for each quantity of interest. Thus, the weights generally differ across quantities of interest. Weight values lie between -1 and 1 , where a larger absolute value indicates greater importance of the respective parameter. In Fig. 2, p2 is more important than p3. The weights are subsequently used to discover a lowdimensional relationship between the input parameters and output quantity of interest. The active variable ( $x$ axis of sufficient summary plot) is a weighted combination of normalized input parameters using the computed weights. The sign of the weight determines which direction the active variable will move if the corresponding parameter is increased or decreased. For example, because the p1 input parameter in Fig. 2 has a large, positive weight $w_{1}$, if its assigned value were to increase, it would result in a larger (more positive) active variable. This translates to a larger value for the quantity of interest due to the positively sloped relationship in the sufficient summary plot. Conversely, an increase in the p2 parameter value would result in a more negative active variable and decrease the quantity of interest because it has a negative weight $w_{2}$. The sufficient summary plots must 


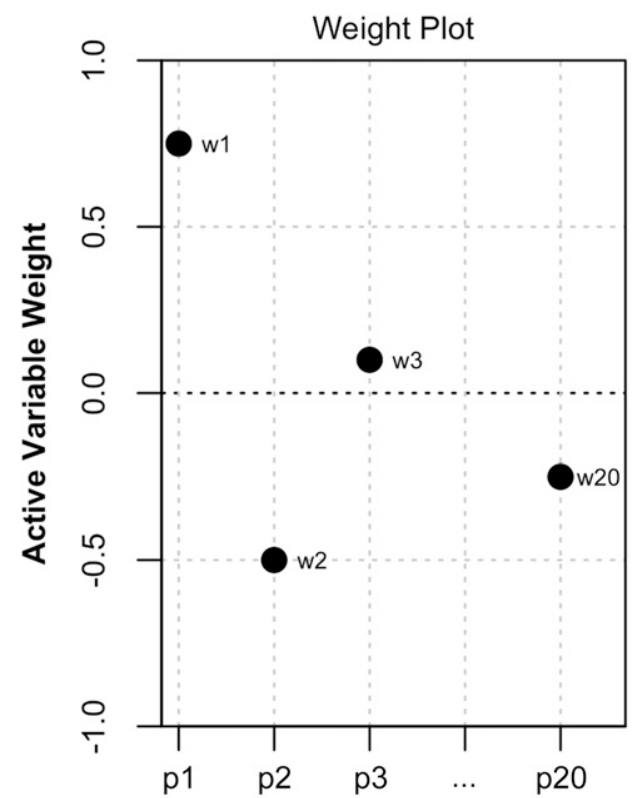

Input Parameter Name

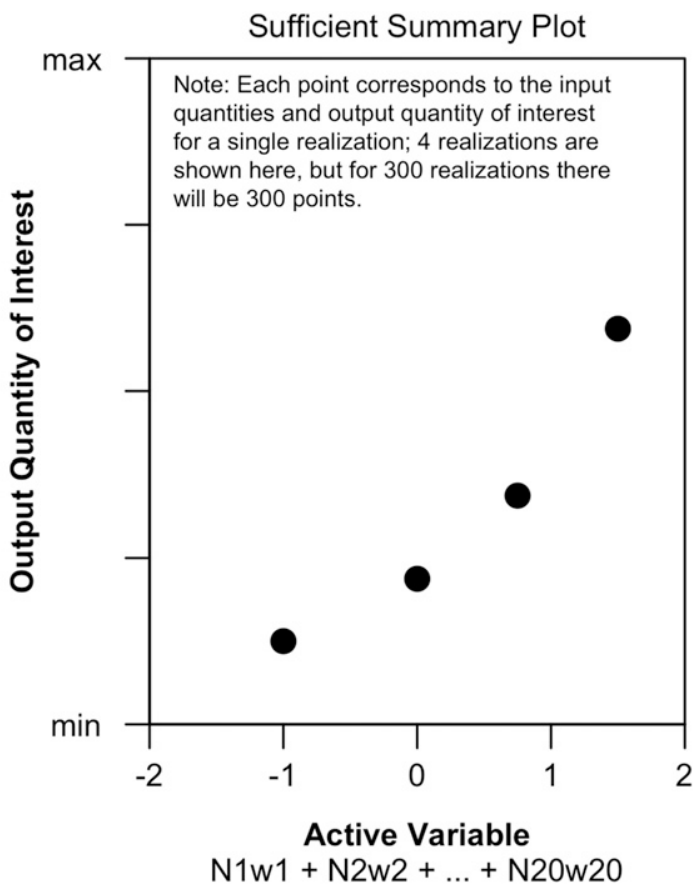

FIG. 2. General example of weight and sufficient summary plots generated by applying the active subspace method; $N_{1}$ and $w_{1}$ correspond to the normalized input parameter value and active variable weight, respectively, of parameter $\mathrm{p} 1$. The number of input parameters is not limited to a certain quantity; 20 corresponds to the number of input parameters investigated as part of this study.

exhibit a near-univariate trend for the active variable weights to have meaning. When the input-output relationship has a flatter slope, changes in input values, captured through the active variable, translate to smaller changes in the output quantity of interest, even when a weight is large.

The sensitivity analyses provided by the active subspace method depend on the ranges chosen for the
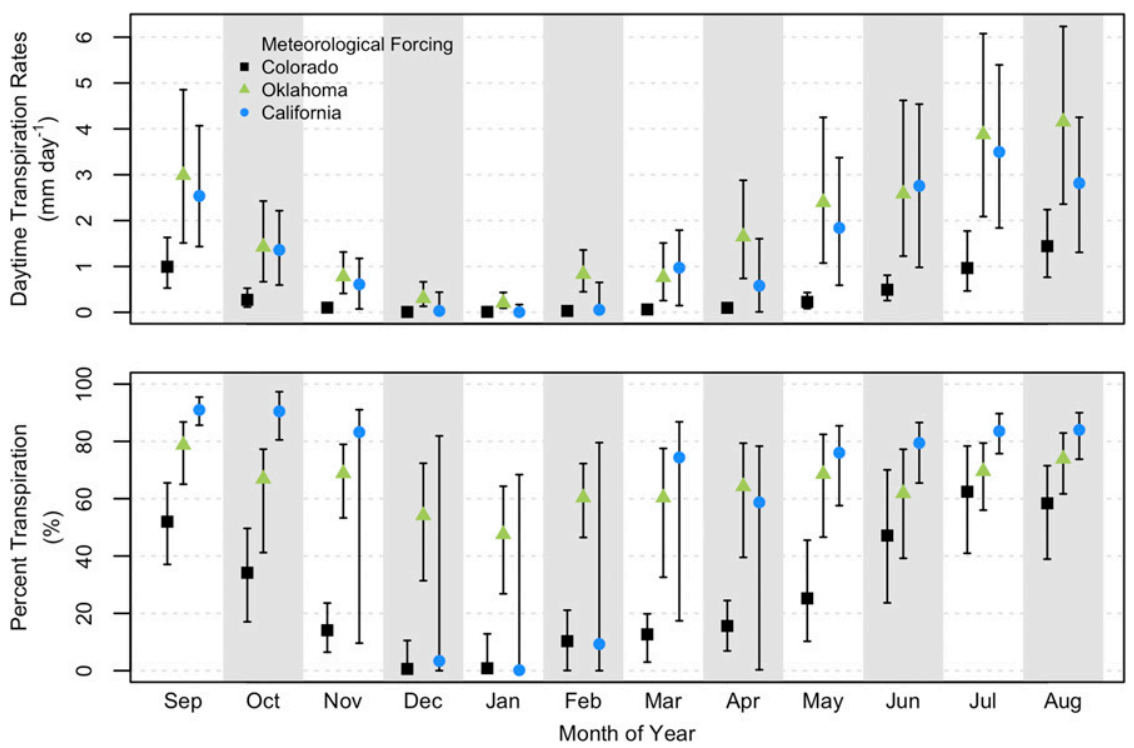

FIG. 3. Monthly transpiration rates and contribution of transpiration to total latent heat flux from all realizations of three meteorological forcing datasets. The symbols correspond to the median and the lower and upper bars correspond to the first and third quartiles, respectively. 
inputs. The range for each parameter was obtained from field measurement and model documentation literature (Table 1). Ranges were set to $10 \%$ above and below default values in cases where magnitude information could not be located. Prior to the random sampling, we performed sweep simulations where each parameter value was changed one at a time to intermediate values throughout the possible range. Given the results from 76 year-long sweep simulations $\left(\approx 8760 \mathrm{~h} \mathrm{yr}^{-1} \times 76\right.$ sweep simulations $\times 3$ forcing sets $\approx 2$ million h of output data), we adjusted the ranges of two parameters to avoid unrealistic outputs (compared to the results produced from simulations with default values).

\section{Results and discussion}

\section{a. Sensitivity differences by location}

Processed outputs from PF-CLM show that daytime transpiration rates and contributions to the total latent heat flux vary based on location and time of year (Fig. 3). Figures 3 (top) and (bottom) contain data from approximately 3.8 million $\mathrm{h}( \pm 4200$ daylight $\mathrm{h} \times$ 300 simulations $\times 3$ forcing sets). Transpiration rates from the columns forced with Oklahoma and California (average year) data have similar monthly median and interquartile ranges and resulted in higher transpiration rates than the column forced with Colorado data. Transpiration percentages from the Colorado and California forcings displayed stronger seasonal behavior than percentages associated with the Oklahoma forcing, which remained between $40 \%$ and $80 \%$. Percentage results from the California forcing showed the smallest interquartile ranges during spring and summer months, but the largest interquartile ranges occurred during the rainy, winter season when both transpiration and canopy evaporation occurs. Even though results in Fig. 3 were obtained by applying specific one-dimensional forcing data to single columns, the approximate contribution of transpiration to the latent heat flux is similar to results from global modeling studies (Lawrence et al. 2007) and field-scale observational studies completed in the United States (Schlaepfer et al. 2014). Regardless of seasonal and geographic variability, transpiration rates and contributions to latent heat were the largest during summer months.

Of the 20 stomatal resistance and photosynthesis parameters evaluated, between four and nine emerged as important (active variable weight magnitude $>0.25$ ) for modeled estimates of transpiration and stomatal resistance (Table 3, Figs. 4a,c). The most important
TABLE 3. Summary of parameters with active variable weight magnitude $>0.25$ for all sites.

\begin{tabular}{|c|c|c|c|c|c|}
\hline & \multirow[b]{2}{*}{ Colorado } & \multirow[b]{2}{*}{ Oklahoma } & \multicolumn{3}{|c|}{ California } \\
\hline & & & Avg & Wet & Dry \\
\hline \multicolumn{6}{|c|}{ Transpiration } \\
\hline $\mathrm{bp}$ & $\times$ & $\times$ & $\times$ & $\times$ & $\times$ \\
\hline $\mathrm{kc} 25$ & $\times$ & $\times$ & $\times$ & $\times$ & $\times$ \\
\hline $\mathrm{mp}$ & $\times$ & $\times$ & $\times$ & $\times$ & $\times$ \\
\hline ocr & & $\times$ & $\times$ & $\times$ & $\times$ \\
\hline qe25 & & & & $\times$ & \\
\hline vcm 25 & $\times$ & $\times$ & $\times$ & $\times$ & $\times$ \\
\hline wj1 & $\times$ & $x$ & $\times$ & $\times$ & $\times$ \\
\hline \multicolumn{6}{|c|}{ Sunlit stomatal resistance } \\
\hline ako & & $x$ & & $x$ & \\
\hline avcmx & $\times$ & & & & \\
\hline bp & $\times$ & $x$ & $\times$ & $\times$ & $\times$ \\
\hline ecp & & $\times$ & & $x$ & \\
\hline hv & & $\times$ & & & \\
\hline $\mathrm{kc} 25$ & $\times$ & $x$ & $x$ & $x$ & $x$ \\
\hline ko25 & & $\times$ & & $\times$ & \\
\hline $\mathrm{mp}$ & $\times$ & $x$ & $\times$ & $\times$ & $\times$ \\
\hline ocr & & $\times$ & $x$ & $x$ & $\times$ \\
\hline qe25 & $\times$ & $x$ & $\times$ & $\times$ & \\
\hline vcm 25 & $\times$ & $\times$ & $\times$ & $\times$ & $\times$ \\
\hline wj1 & $\times$ & $\times$ & $\times$ & $x$ & $\times$ \\
\hline \multicolumn{6}{|c|}{ Shaded stomatal resistance } \\
\hline bp & $\times$ & $\times$ & $\times$ & $\times$ & $\times$ \\
\hline hv & $\times$ & & & & \\
\hline $\mathrm{mp}$ & $\times$ & $\times$ & $\times$ & $\times$ & $\times$ \\
\hline ocr & & $\times$ & $\times$ & $\times$ & \\
\hline qe25 & $\times$ & $x$ & $\times$ & & $\times$ \\
\hline vcm 25 & $\times$ & & & & \\
\hline wj1 & $\times$ & $x$ & $\times$ & $\times$ & $\times$ \\
\hline
\end{tabular}

parameters included the slope and intercept of the Ball-Berry parameterization along with parameters used to compute RuBisCO- and light-limited rates of photosynthesis. Sufficient summary plots associated with monthly-averaged transpiration rates for each site exhibited similar seasonal behavior; however, the magnitude and range of the output quantity varied by forcing (Figs. 4d,f). Less incoming shortwave radiation and lower air temperatures resulted in low transpiration rates for the Colorado forcing (Fig. 4d), whereas more incoming shortwave radiation and warm air temperatures led to higher transpiration rates for the Oklahoma (Fig. 4e) and California forcings (Fig. 4f). Compared to transpiration rates from the average year at the Tonzi Ranch site, estimated rates were similar during the wetter year (Fig. S5 in the supplemental material) and slightly lower for the dry year (Fig. S7 in the supplemental material). Differences in transpiration rate magnitudes are primarily due to atmospheric forcing since vegetation is likely not limited by water due to high water tables in the single-column domains. 

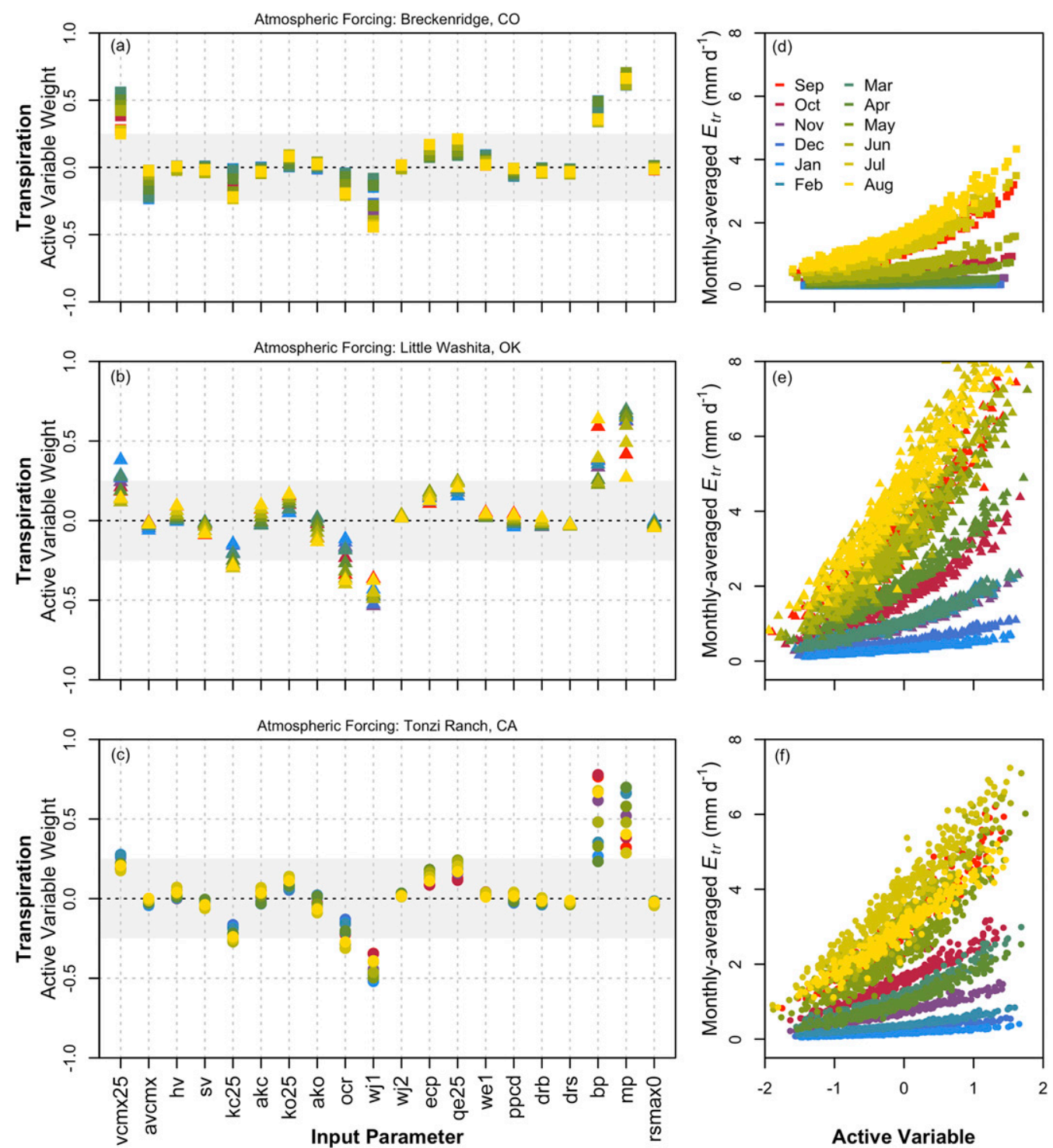

FIG. 4. Active variable weights and sufficient summary plots for monthly-averaged transpiration using forcing from (a),(d) Breckenridge; (b),(e) Little Washita; and (c),(f) Tonzi Ranch (from September 2002 to August 2003).

In an actual watershed there are spatial variations of water-table depths, soil properties, and land-cover types that are not captured by a single-column domain. However, if we consider a site-specific model as a combination of single columns with different subsurface and surface characteristics, we would expect transpiration rates to vary across the domain. Additional singlecolumn simulations using site-specific water-table depth, soil type, and land-use information from the Little Washita watershed were completed to confirm that actual site conditions do not influence which parameters control transpiration estimates. Figure 5 shows that even when the hypothetical domain was updated to better represent actual site conditions, important parameters (vcmx25, kc25, ocr, wj1, bp, and $\mathrm{mp}$ ) remained the same (Figs. 4b, 5a,b). However, changes in subsurface conditions and vegetation type did impact the magnitudes of the transpiration flux (Figs. 5c,d). Trees that have access to shallower subsurface water (Fig. 4e) sustained higher rates of transpiration throughout the summer months and transpired at rates greater than trees that did not (Fig. 5c). Grasslands and deciduous trees had similar averaged transpiration rates and seasonal behavior when there was a deeper water table (Figs. 5c,d). The parameter sensitivities identified in this research are a result of the model parameterization, not 

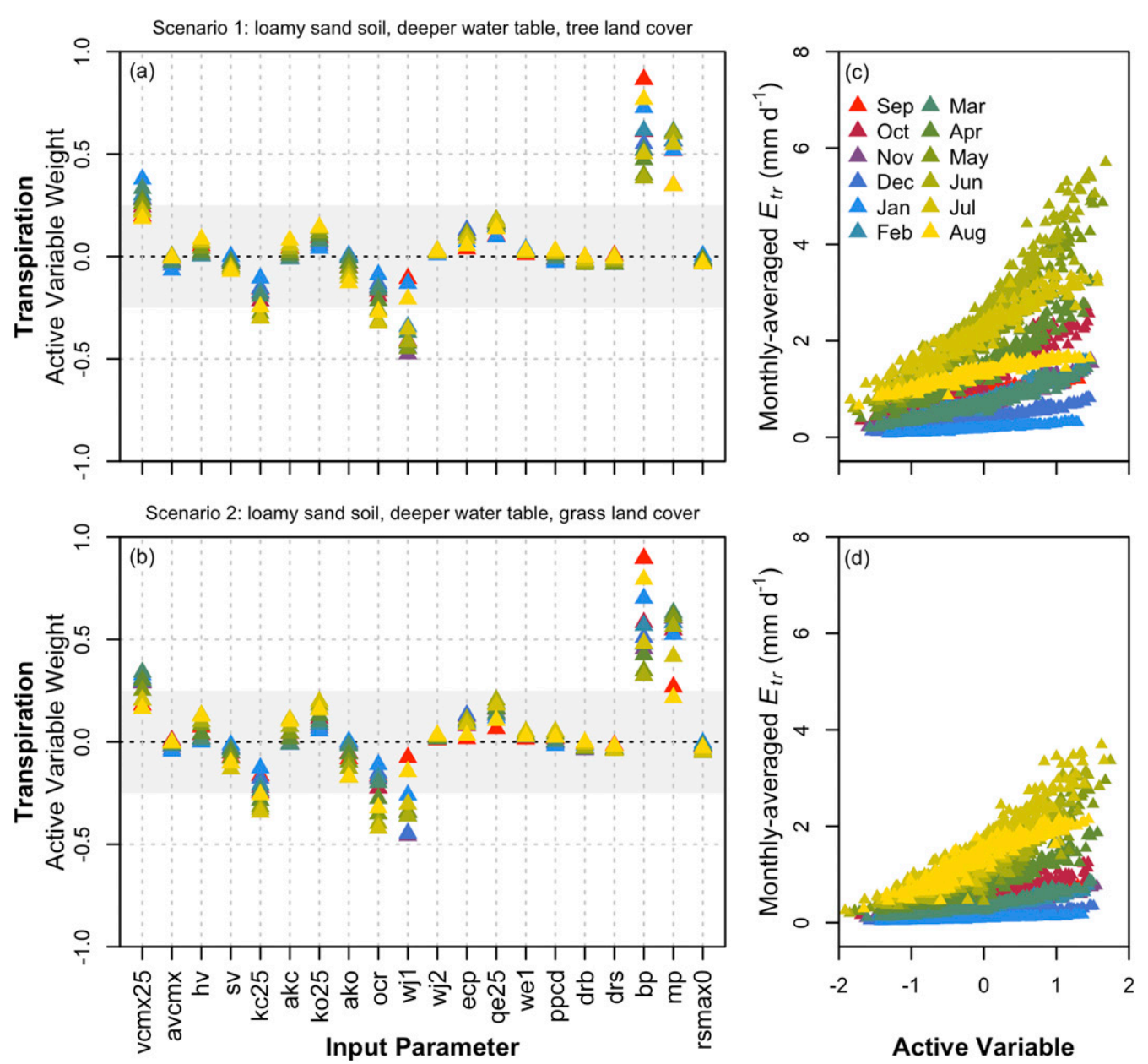

FIG. 5. Active variable weights and sufficient summary plots for monthly-averaged transpiration and stomatal resistance for variations of subsurface and surface properties (scenarios 1 and 2) using Little Washita watershed forcing from September 1998 to August 1999.

site-specific subsurface, land surface, or atmospheric conditions.

\section{b. Time-varying sensitivities and behaviors}

Closer inspection of Fig. 4 reveals that input parameter weights and sufficient summary relationships vary throughout the year. Because parameter sensitivities are quite similar for all three sites, the remaining discussion about time-varying sensitivities and behaviors is focused on the 300 realizations forced with Tonzi Ranch atmospheric data from the most average year (2002-03). Vegetation measurements (Osuna et al. 2015; Xu and Baldocchi 2003), PF-CLM modeling (Gou 2014), and other hydrology research (Miller et al. 2010) have been completed at the California site. Additional information from simulations completed with forcing from wet (2005-06) and dry (2007-08) years at the California site as well as for the
Colorado and Oklahoma sites is located in the supplemental material.

\section{1) SENSitivities ASSOCiated With MONTHLY AVERAGED DAYTIME QUANTITIES}

Given the seasonal variations shown in Figs. 3 and 4, we first evaluated parameter sensitivities associated with monthly-averaged daytime quantities of interest. The slope (mp) and intercept (bp) parameters that must be specified as part of the Ball-Berry stomatal resistance model were consistently important for stomatal resistance (Fig. 6) as well as for transpiration (Fig. 4c) estimates. Parameter bp was important all year for monthly-averaged $r_{s}$ computations associated with the shaded portion of the canopy. While maintaining their overall importance, there was much variation in the weight magnitudes of bp and $\mathrm{mp}$ throughout the year (Figs. 7a,b). More parameters are important for $r_{s \text {,sun }}$ 


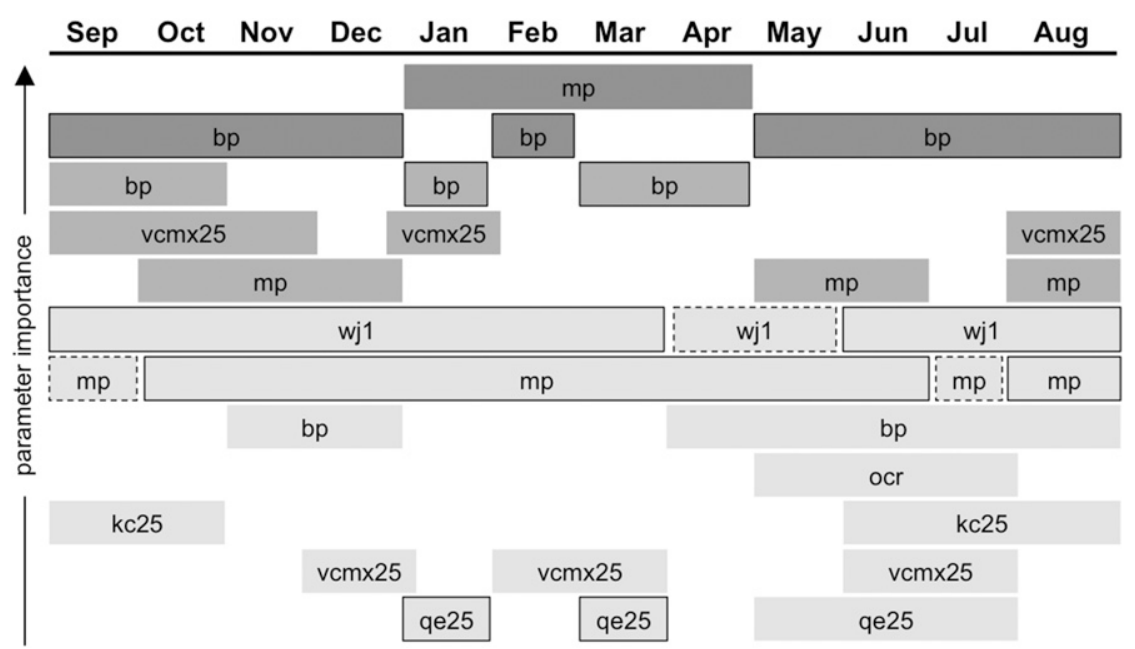

FIG. 6. Relative importance of input parameters for monthly-averaged sunlit and shaded stomatal resistance quantities. Shading corresponds to the magnitude of the active variable weight: dark gray (0.75-1; more important), gray (0.50-0.75), and light gray (0.25-0.50; less important). The borders indicate which fraction of the canopy exerts the control: shaded (solid black), sunlit (no line), or both (dashed line).

than for $r_{s, \text { sha }}$, especially in spring and summer months. The maximum rate of carboxylation (vcmx25) was not important for monthly-averaged $r_{s, \text { sha }}$ (Fig. 7b), but was important for monthly-averaged $r_{s, \text { sun }}$ in the late summer and early fall months (Fig. 7a). The hard-coded lightlimited photosynthesis rate parameter (wj1) influenced monthly-averaged $r_{s, \text { sha }}$ and was regularly among the most important parameters for transpiration. Three other hard-coded photosynthesis parameters $(\mathrm{kc} 25$, ocr, and qe25) consistently had active variable weight magnitudes larger than 0.25 . In general, weights associated with monthly-averaged $r_{s, \text { sun }}$ quantities were more variable and seasonally dependent than those for $r_{s, \text { sha }}$ (Figs. 7a,b).

The relationship between the input parameters and monthly daytime-averaged stomatal resistance values were similar for all months in the shaded portion of the canopy (Fig. 7d) and varied slightly during the fall months for the sunlit portion of the canopy (Fig. 7c). However, the sufficient summary plot for monthly daytime-averaged transpiration rates showed much variation throughout the year (Fig. 4f). The slope of the input-output relationship was flattest during the winter, increased during the spring to reach the steepest slope during the summer, and then decreased during the fall. This seasonal behavior translated to high transpiration rates during summer months and lower rates during energy-limited winter months when the leaf area index is also at its minimum. When the slope is the steepest (May-September), the range of possible transpiration rates is the largest. Steeper slopes also indicate greater sensitivity to changes in important input parameter values. For example, bp was among the most important parameters for averaged transpiration rates in both June and October (Fig. 4c). However, changes in the value of bp will influence transpiration in June much more than in December because of the slope of the input-output relationship (Fig. 4f).

It is possible to physically estimate values for several parameters identified as important to compute transpiration and stomatal resistance in PF-CLM. Osuna et al. (2015) and Xu and Baldocchi (2003) calculated maximum carboxylation and electron transfer rates from gas exchange measurements collected periodically throughout the growing season at the Tonzi Ranch field site. These two factors, along with leaf nitrogen content, influence the rate of photosynthesis and, therefore, stomatal resistance. Parameter vcmx 25 is a constant in PF-CLM, but observations show that its value varies seasonally; the magnitude is highest in the spring and decreases throughout the summer (Osuna et al. 2015; Xu and Baldocchi 2003). The vcmx25 values used in the realizations for this research are lower than the spring peak values but lie within the range of observations obtained at the Tonzi Ranch field site. While vcmx 25 has a high active variable weight with respect to the sunlit stomatal resistance (Fig. 7a), the magnitude of its importance does not translate to transpiration (Fig. 4c). Thus, if transpiration was the quantity of interest in a modeling study, a vcmx 25 value that does not represent observations should not have a substantial impact on transpiration estimates. Observed values of the maximum electron transfer rate are also shown to vary throughout the year (Osuna et al. 2015; $\mathrm{Xu}$ and Baldocchi 2003). In PF-CLM, the electron transfer rate 

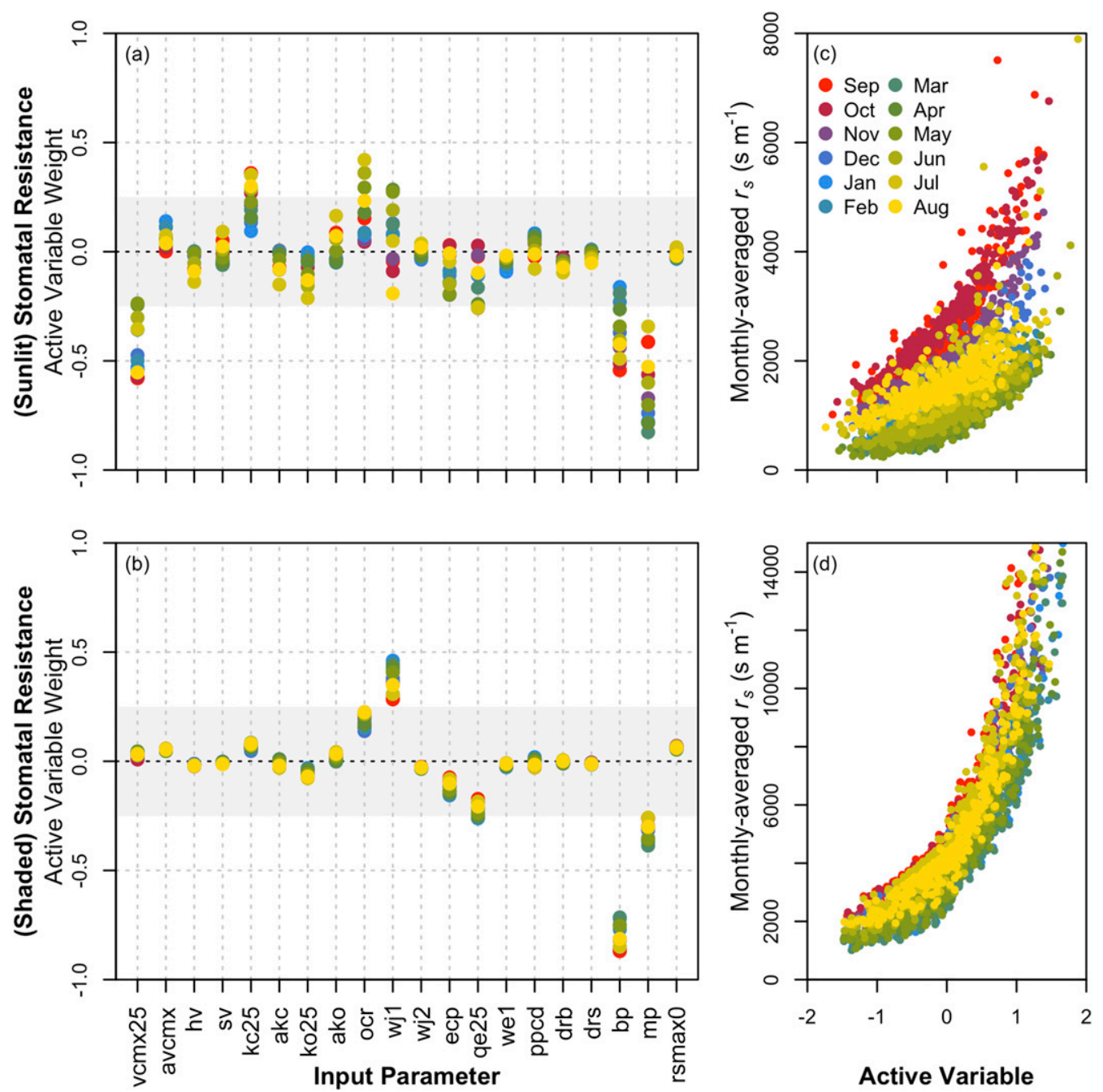

FIG. 7. (a),(b) Active variable weights and (c),(d) sufficient summary plots for monthly-averaged stomatal resistance using Tonzi Ranch forcing from September 2002 to August 2003.

$J[(\mathrm{~A} 11)]$ is a computed quantity that depends on the photon energy content (ecp), quantum efficiency (qe25), and PAR. PAR is derived from shortwave radiation, which is included as part of the forcing data, and varies diurnally and seasonally for each site. Currently, measurements of quantities like the electron transfer rate are not available at the frequency and duration needed to be input directly into PF-CLM. Xu and Baldocchi (2003) also calculated the Ball-Berry slope parameter from gas exchange measurements. They found that $\mathrm{mp}$ remained constant throughout periods of water stress and high air temperatures. This finding suggests that use of a constant $\mathrm{mp}$ value specific to a particular vegetation type may be adequate to represent physical behavior. Important parameters (vcm 25 , qe25, and $\mathrm{mp}$ ) predicted from this sensitivity analysis align with factors that control vegetation dynamics.

\section{2) Sensitivities ASSOciated With SUMMER HOURLY AVERAGED DAYTIME QUANTITIES}

When the quantities of interest are averaged by hour during June-August, the weights (Figs. 8, 9a-c) and sufficient summary plots (Figs. 9d-f) capture changes throughout the diurnal cycle as opposed to seasonal changes shown by the monthly-averaged plots (Figs. 4, 7). The Ball-Berry slope and intercept parameters exerted strong influence over hourly-averaged $r_{s \text {,sun }}$ and $r_{s \text {,sha }}$ throughout the entire day (Figs. 8, 9b,c). Hourly estimates of stomatal resistance from the sunlit portion of the canopy were also influenced by $\mathrm{kc} 25$, vcmx 25 , and wj 1 . The maximum ratio of oxygenation to carboxylation (ocr) and quantum efficiency (qe25) further influenced sunlit stomatal resistance at dawn and dusk, but ocr also contributed to estimates of shaded and sunlit 


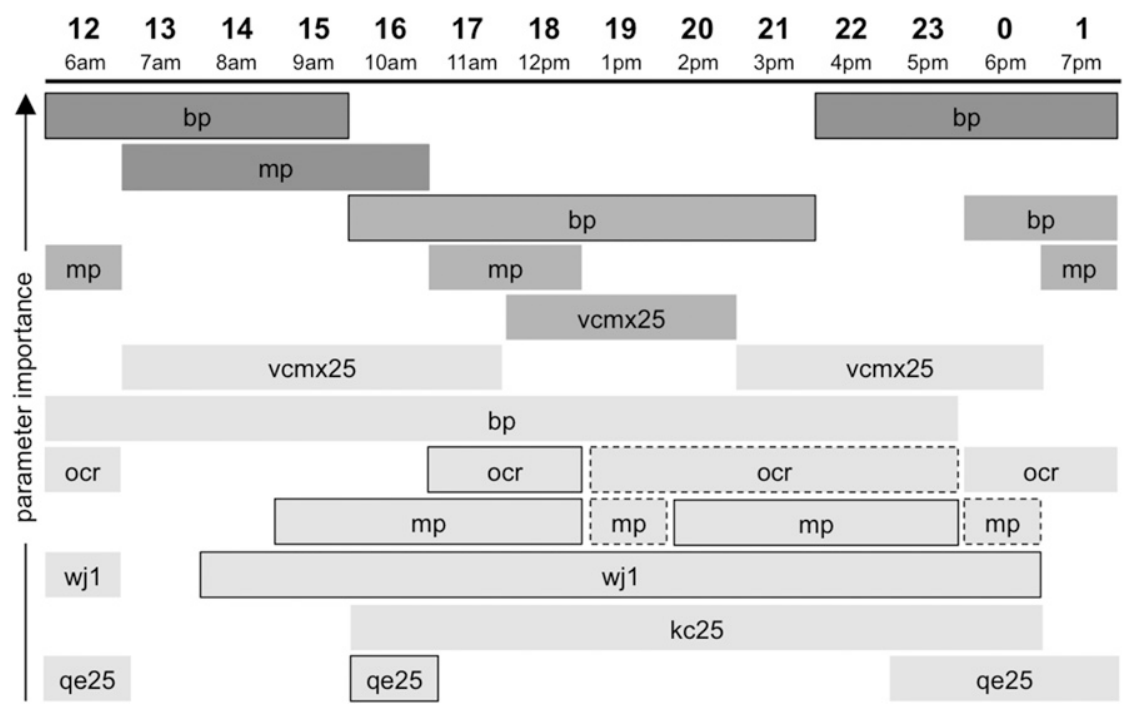

FIG. 8. Relative importance of input parameters for hourly-averaged sunlit and shaded stomatal resistance quantities for each UTC hour (local time shown below). Shading corresponds to the magnitude of the active variable weight: dark gray ( $0.75-1$; more important), gray $(0.50-0.75)$, and light gray (0.25-0.50; less important). The borders indicate which fraction of the canopy exerts the control: shaded (solid black), sunlit (no line), or both (dashed line).

stomatal resistance in the afternoon (Fig. 8). Fewer parameters influenced the quantities of interest at dawn and dusk compared to midday, afternoon, and early evening hours when transpiration rates were the largest. The relationship between the input parameters and hourly stomatal resistance was similar for all hours (Figs. 9e,f); however, resistance values spread farther from the perceived univariate trend compared to the sufficient summary plots of the monthly-averaged quantities (Figs. 7c,d). As expected, many important input parameters for $r_{s, \text { sun }}$ and $r_{s \text { sha }}$ were also important for transpiration rates (Fig. 9a). Transpiration rate behavior reflected the diurnal cycle; rates were lowest in the morning, increased during midday and afternoon hours, and then decreased later in the day (Fig. 9d). Furthermore, transpiration rates were most sensitive to input parameters during the middle of the day and showed a wider range of possible values when averaged by hour (Fig. 9d) than by month (Fig. 4f).

Photosynthesis parameters identified as important for hourly-averaged $r_{s, \text { sun }}$ values correspond to RuBisCOand light-limited rates of photosynthesis. Since qe25 is the only important $r_{s, \text { sun }}$ parameter exclusively used to compute the light-limited rate, Fig. 8 showed that the light-limited rate controlled $r_{s \text { sun }}$ during morning and evening hours (ako, kc25, ko25, and ocr parameters are used to compute both photosynthesis rates). However, photosynthesis rates from the simulation using default parameter values were rarely limited by light and were almost always limited by the RuBisCO rate for the sunlit portion of the canopy (crosses in Fig. 10). It is not until results from all realizations were considered that two limiting rates for $r_{s, \text { sun }}$ emerged. Conversely, results from the default simulation suggest that $r_{s, \text { sha }}$ is limited by both $\mathrm{RuBisCO}$ and light, but predominately only one rate (i.e., light limited) occurred in the other realizations. The export-limited rate rarely controlled the stomatal resistance for either portion of the canopy. The inconsistency between which rate limits photosynthesis in the default simulation and the 300 realizations suggests that the default parameter values or the photosynthesis parameterization is not good enough to predict the controlling rate of photosynthesis. The choice of input parameter values influences which of the three rates is used to compute the stomatal resistance.

\section{Conclusions}

This analysis informs PF-CLM users about which photosynthesis and Ball-Berry stomatal resistance parameters should be carefully specified. Many of the parameters identified as important for latent heat estimates in other studies (e.g., Göhler et al. 2013; Prihodko et al. 2008; Li et al. 2013) agree with the parameters identified here. Modeled estimates of transpiration may also be improved when vegetation properties are more accurately assigned. For example, Sulis et al. (2015) found that modeled energy and carbon flux estimates using a platform that includes PF; CLM, version 3.5; and an atmospheric component aligned with 

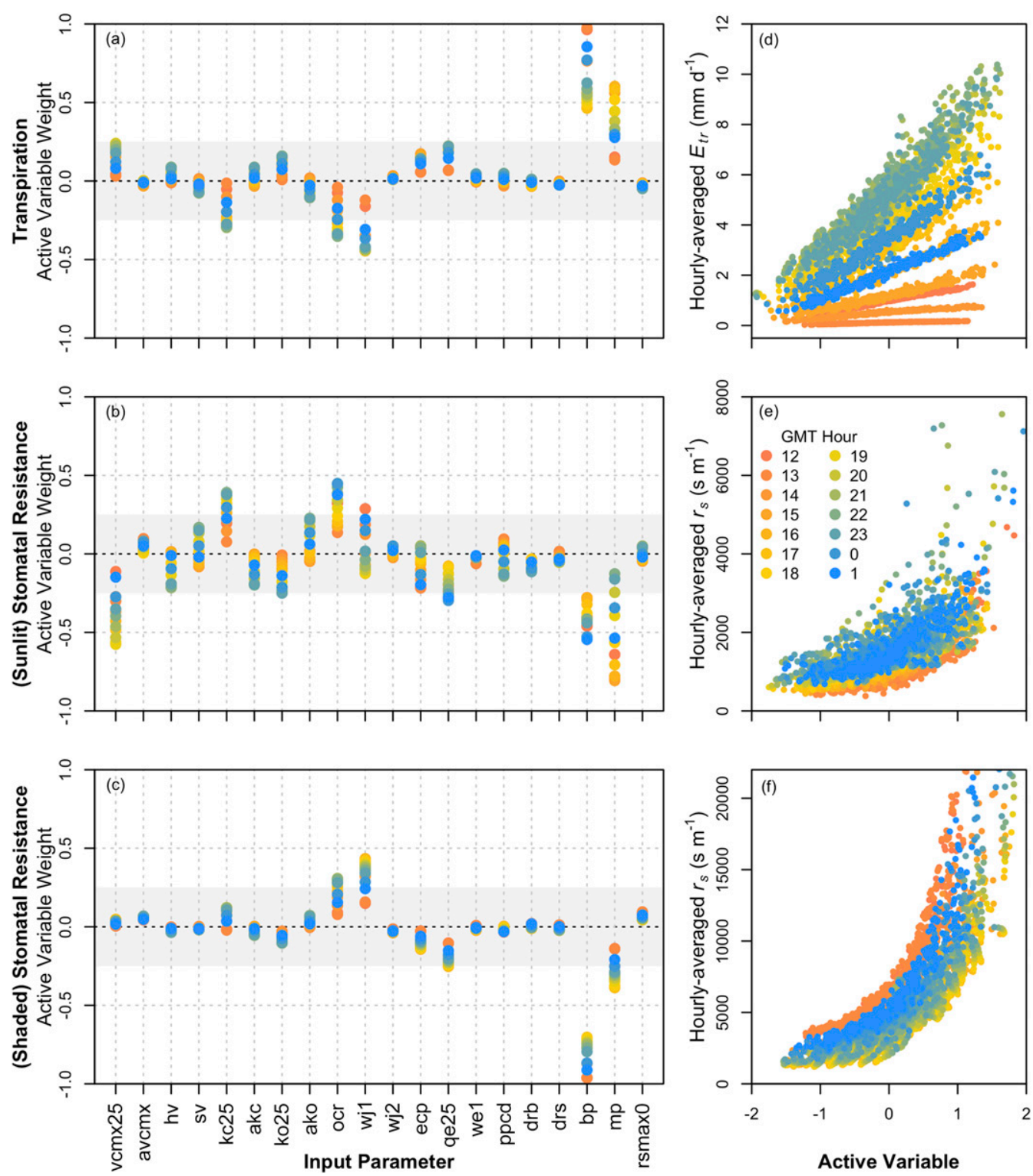

FIG. 9. (a)-(c) Active variable weights and (d)-(f) sufficient summary plots for hourly-averaged transpiration and stomatal resistance using Tonzi Ranch forcing from June to August 2003.

observations better when default parameter values were updated to match crop-specific photosynthesis (e.g., vcmx 25, qe25, and six others not included in this study) and Ball-Berry slope parameters. The active variable weights and sufficient summary plots provide one explanation to why modeled estimates changed when the vegetation parameters were updated: namely, the model is sensitive to $\mathrm{mp}, \mathrm{vcm} \times 25$, and qe25. Results from this sensitivity analysis also support the update to CLM, version 4.5 , where $\mathrm{mp}$ and $\mathrm{vcm} \times 25$ parameter values are assigned based on PFT (Oleson et al. 2013). We recommend that modelers consider existing databases or documentation of field-based stomatal resistance and photosynthesis values when specifying important model parameters.

This sensitivity analysis also provides information about insensitive parameters. The parameter used to specify the partial pressure of carbon dioxide in the atmosphere (ppcd) had a low active variable weight magnitude $(<0.15)$ for all monthly- and hourly-averaged quantities. Also, ppcd had a small effect on stomatal resistance and transpiration estimates. Experiments indicate that stomatal resistance is sensitive to the atmospheric carbon dioxide concentration: an increase in carbon dioxide will increase stomatal resistance and decrease transpiration (Field et al. 1995). However, the 


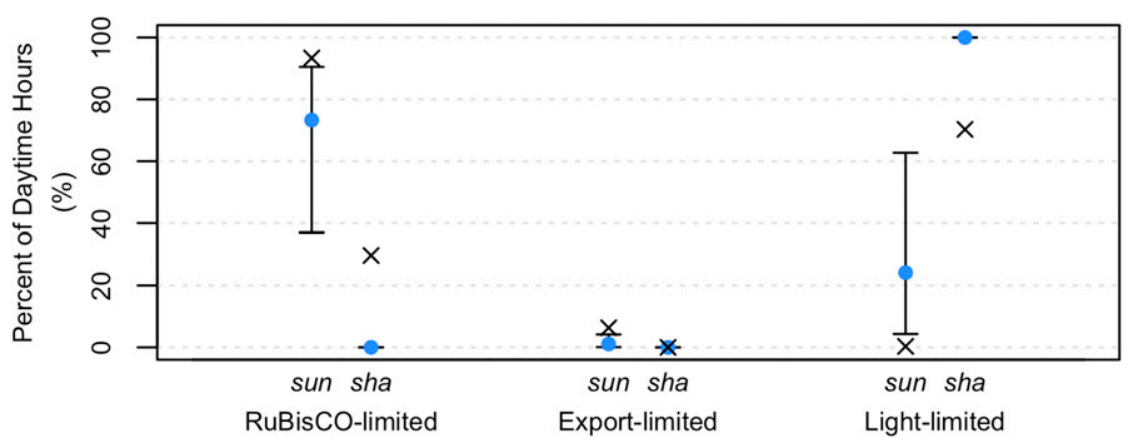

FIG. 10. Percentage of summer daytime hours each photosynthesis rate limits the stomatal resistance computation using the Tonzi Ranch forcing. The circles correspond to the median and the lower and upper bars correspond to the first and third quartiles, respectively. The crosses correspond to percentages associated with the simulation where default photosynthesis and stomatal resistance values were used.

effect of concentration changes on canopy transpiration is expected to be less than the impact to stomatal resistance at the leaf scale (Field et al. 1995). The response of PF-CLM compared to experimental evidence suggests that the current parameterization may not be adequate to predict responses of stomatal resistance and transpiration to increased atmospheric $\mathrm{CO}_{2}$ concentrations. Nitrogen concentrations within plant foliage are also known to influence plant function (Drake et al. 1997; Bonan et al. 2012). Aside from one foliage nitrogen factor (default value set to 1), no other nitrogen parameters are present in PF-CLM; therefore, sensitivities to nitrogen parameters were not evaluated. It will be important to assess and document sensitivity changes as the stomatal resistance parameterization is adjusted.

In conclusion, the active subspace method identified that approximately one-half of the 20 stomatal resistance and photosynthesis parameters evaluated exert moderate-to-high influence (active variable weight magnitude $>0.25$ ) on estimates of water transfer between the subsurface and atmosphere, regardless of geographic location. The two Ball-Berry parameters, $\mathrm{mp}$ and $\mathrm{bp}$, consistently had large active variable weights. In addition, and in agreement with our hypothesis, the influence of important parameters on averaged stomatal resistance and transpiration quantities varied both seasonally and diurnally. Input parameter perturbations changed transpiration fluxes the most during midday summertime hours when fluxes are large, which concurs with findings by Prihodko et al. (2008). Sensitivity analyses quantify the parameters' numerical importance, but input from plant physiologists would add insight and physical meaning to the equations and parameters used to model transpiration. Physical explanations and values for many important model parameters are still lacking. Data collection and modeling efforts are synergistic - field researchers provide data and insight sought by modelers, and modelers use this information to evaluate how parameters are incorporated and specified within a model. Hydrology must integrate measurements and models to address contemporary water resource concerns; the sensitivity analysis we provide can assist at this interface to inform which vegetation measurements are needed to inform and better understand transpiration estimates from land surface models.

Acknowledgments. This work was completed with the support of the National Science Foundation Water Sustainability and Climate Grant WSC-1204787 (J.L.J. and R.M.M.) and the United States Department of Energy Office of Science, Office of Advanced Scientific Computing Research, Applied Mathematics program under Award DE-SC-0011077 (P.G.C.).

\section{APPENDIX}

\section{PF-CLM Photosynthesis Equations}

The rate of photosynthesis $A$ ( $\mu$ mol photon $\mathrm{m}^{-2} \mathrm{~s}^{-1}$ ) used to determine the stomatal resistance is taken as the minimum of three computed rates,

$$
A=\min \left(w_{c}, w_{e}, w_{j}\right),
$$

and does not include respiration. The maximum rate of RuBisCO carboxylation (i.e., RuBisCO-limited rate) is computed as

$$
w_{c}=V_{c, \max } \frac{c_{i}-c_{p}}{c_{i}+\left[k_{c}\left(1+\frac{P_{\mathrm{O}_{2}}}{k_{o}}\right)\right]},
$$


where $V_{c, \text { max }}\left(\mu \mathrm{mol} \mathrm{CO} \mathrm{CO}_{2} \mathrm{~m}^{-2} \mathrm{~s}^{-1}\right)$ is the maximum rate of carboxylation; $c_{i}(\mathrm{~Pa})$ is the internal $\mathrm{CO}_{2}$ concentration of the foliage; $P_{\mathrm{O}_{2}}(\mathrm{~Pa})$ is the concentration of oxygen in the atmosphere computed as $0.209 \times P_{\mathrm{atm}}$; and $k_{c}$ and $k_{o}$ are Michaelis-Menten constants for $\mathrm{CO}_{2}$ and $\mathrm{O}_{2}$, respectively. The Michaelis-Menten constants vary as the vegetation temperature $t_{v}\left({ }^{\circ} \mathrm{C}\right)$ deviates from $25^{\circ} \mathrm{C}$ :

$$
k_{i}=k_{i, 25} M_{i}^{\left(t_{v}-25\right) / 10}
$$

where $k_{i, 25}$ is the constant value at $25^{\circ} \mathrm{C}, M_{i}$ is the factor by which the magnitude changes with a $10^{\circ} \mathrm{C}$ increase in temperature, and $i$ can equal either $c$ (for $\mathrm{CO}_{2}$ ) or $o$ (for $\mathrm{O}_{2}$ ). Both constants are used to compute the $\mathrm{CO}_{2}$ compensation point $c_{p}(\mathrm{~Pa})$ :

$$
c_{p}=0.5 \frac{k_{c}}{k_{o}} P_{\mathrm{O}_{2}} r_{o c}
$$

where $0.5 \mathrm{~mol}$ of $\mathrm{CO}_{2}$ is released during the reaction between ribulose bisphosphate and $1 \mathrm{~mol}$ of $\mathrm{O}_{2}$ and $r_{o c}$ (unitless) is the maximum ratio of oxygenation to carboxylation.

The magnitude of $V_{c, \max }$ is computed as

$$
V_{c, \max }=\frac{f_{1}\left(t_{v}\right)}{f_{2}\left(t_{v}\right)} \beta
$$

and is influenced by vegetation temperature and by the amount of water in the soil column, which is incorporated through the soil resistance factor $\beta$ (unitless). The temperature dependency is applied through two functions:

$$
f_{1}\left(t_{v}\right)=V_{c, \max 25} M_{V}^{\left(t_{v}-25\right) / 10},
$$

which has a similar form to (A3) and

$$
f_{2}\left(t_{v}\right)=1+\exp \left[\frac{-H_{V}+S_{V}\left(t_{v}+273.16\right)}{8.314\left(t_{v}+273.16\right)}\right],
$$

where $H_{V}\left(\mathrm{~J} \mathrm{~mol}^{-1}\right)$ is a deactivation constant, $S_{V}\left(\mathrm{~J} \mathrm{~mol}^{-1} \mathrm{~K}^{-1}\right)$ is an entropy constant, and $8.314 \mathrm{~J} \mathrm{~mol}^{-1} \mathrm{~K}^{-1}$ is the universal gas constant. Soil saturation $S$ (unitless) values from the upper 10 layers $l$ in PF are used to determine the soil resistance factor

$$
\beta=\sum_{l=1}^{l=10}\left[f_{\text {root }, l}\left(\frac{\phi_{l} S_{l}-\phi_{l} S_{\mathrm{wp}}}{\phi_{l} S_{\mathrm{fc}}-\phi_{l} S_{\mathrm{wp}}}\right)\right],
$$

where $f_{\text {root }, l}$ (unitless) is the fraction of roots in each layer, $\phi$ (unitless) is porosity, and $S_{\mathrm{wp}}$ (unitless) and
$S_{\mathrm{fc}}$ (unitless) are degrees of saturation that correspond to the wilting point and field capacity, respectively. This form of $V_{c, \max }$ assumes that $V_{c, \max 25}$ includes the effect of foliage nitrogen concentration variations and does not include any additional adjustments for day length or vertical nitrogen gradients (Oleson et al. 2013).

The second way that the rate of photosynthesis can be constrained is when the concentration of products (i.e., sugars) build up within the leaf (i.e., export- or sucroselimited rate):

$$
w_{e}=3 T_{p}=3 \times 0.167 V_{c, \max },
$$

where the triose phosphate utilization rate $T_{p}$ $\left(\mu \mathrm{mol} \mathrm{m}{ }^{-2} \mathrm{~s}^{-1}\right)$ is approximated as a fraction of $V_{c, \max }$.

Last, photosynthesis rates can be limited by the amount of light needed to regenerate $\mathrm{RuBisCO}$ enzymes (i.e., light-limited rate):

$$
w_{j}=J \frac{c_{i}-c_{p}}{n_{1} c_{i}+n_{2} c_{p}},
$$

where $n_{1}$ and $n_{2}$ are factors preceding $c_{i}$ and $c_{p}$, respectively, and $J\left(\mu \mathrm{molCO} \mathrm{Cm}^{-2} \mathrm{~s}^{-1}\right)$ is the electron transport rate

$$
J=E_{p} \mathrm{qe}_{25} \mathrm{PAR}
$$

where $E_{p}$ is the photon energy content ( $\mu$ mol photons $\mathrm{J}^{-1}$ ) and $\mathrm{qe}_{25}\left(\mu \mathrm{mol} \mathrm{CO}_{2} \mu\right.$ mol photon $\left.{ }^{-1}\right)$ is the quantum efficiency at $25^{\circ} \mathrm{C}$.

The minimum rate of photosynthesis is first used to compute the $\mathrm{CO}_{2}$ concentration at the leaf surface $c_{s}$ $(\mathrm{Pa})$ :

$$
c_{s}=P_{\mathrm{CO}_{2}}-D_{\mathrm{rb}} r_{b} P_{\mathrm{atm}} A,
$$

where $P_{\mathrm{CO}_{2}}(\mathrm{~Pa})$ is the concentration of $\mathrm{CO}_{2}$ in the atmosphere taken as $x_{\mathrm{CO}_{2}} \times P_{\mathrm{atm}}$, with $x_{\mathrm{CO}_{2}}(\mathrm{ppm})$ being the partial pressure of $\mathrm{CO}_{2} ; D_{\mathrm{rb}}$ is the ratio of the diffusivity of $\mathrm{CO}_{2}$ and water in the boundary layer; and $r_{b}$ is the boundary layer resistance. Finally, $r_{s}$ is solved from (2) using the quadratic equation and $c_{i}$ is calculated from

$$
c_{i}=c_{s}-A P_{\mathrm{atm}} D_{\mathrm{rs}} r_{s},
$$

where $D_{\mathrm{rs}}$ is the ratio of the diffusivity of $\mathrm{CO}_{2}$ and water through leaf stomata.

The rate of photosynthesis [(A2), (A9), and (A10)] and $\mathrm{CO}_{2}$ concentrations at two locations [(A12) and (A13)], along with vapor pressures and specified $m$ and $b$ parameters, are used to compute stomatal resistance using the Ball-Berry parameterization [(2)]. While $m$ 


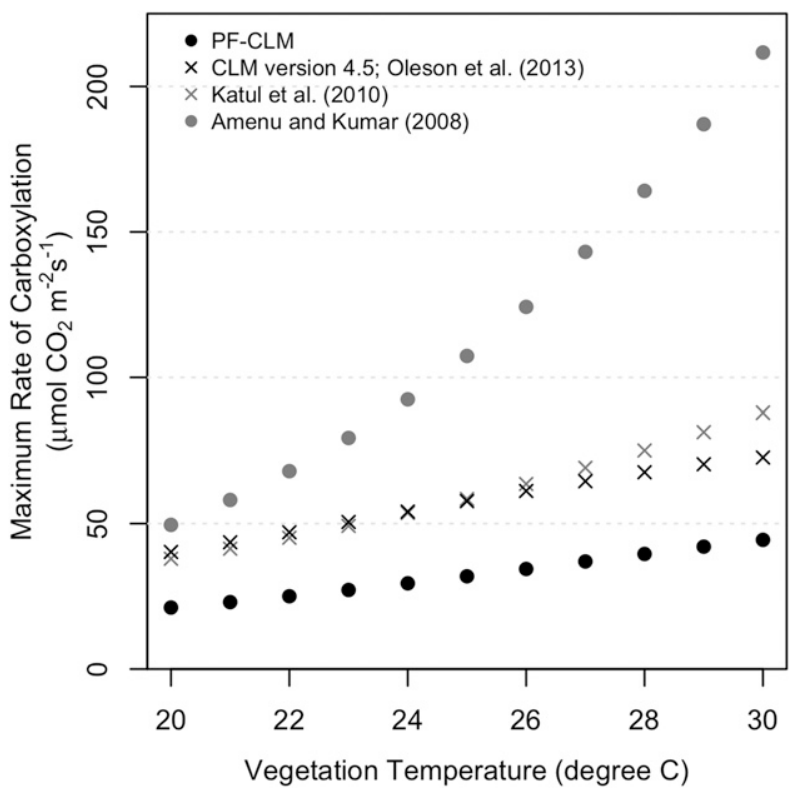

FIG. A1. Relationship between vegetation temperature and max rate of carboxylation for four different parameterizations. The relationship corresponds to deciduous trees in CLM and to evergreen trees for Katul et al. (2010) and Amenu and Kumar (2008). The PFCLM relationship is the same for all vegetation types.

and $b$ are hard coded in PF-CLM, actual values can be obtained from gas exchange measurements using a portable photosynthesis system (e.g., Li-Cor 6400 device). It takes approximately $1-2 \mathrm{~h}$ to complete one set of leaf-scale gas exchange measurements, noting that measurements from several leaves are required at multiple times throughout the growing season ( $\mathrm{Xu}$ and Baldocchi 2003; Osuna et al. 2015; Wilson and Baldocchi 2000). The estimate of $m$ depends on the time step of the gas exchange measurements, where longer time steps produce more realistic values (Xu and Baldocchi 2003). Physical estimates of $m$ and $b$ exist, but they are not widely available.

Most of the above equations are consistent among sources, but $k_{i}(\mathrm{~A} 3), c_{p}(\mathrm{~A} 4), V_{c, \text { max }}(\mathrm{A} 5), w_{j}(\mathrm{~A} 10)$, and $J$ (A11) have been found to differ. Some of these equations are similar in form and contain similar variables but have different coefficient magnitudes $\left(w_{j}\right.$; Arneth et al. 2002; Amenu and Kumar 2008; Gu et al. 2010; Oleson et al. 2013) or vary in how temperature is corrected $\left(k_{i}\right.$ and $V_{c \text {,max }}$; Amenu and Kumar 2008; Katul et al. 2010; Oleson et al. 2013). For example, Fig. A1 compares how the maximum rate of carboxylation changes with vegetation temperature from four different sources. In some cases, like for $c_{p}$ and $J$, equations differ in both form and composition (Chen et al. 1999; Gu et al. 2010; Amenu and Kumar 2008; Oleson et al. 2013). We do not evaluate sensitivities associated with formulation differences given that the purpose of this work is to evaluate the sensitivity of parameters typically held at constant values.

\section{REFERENCES}

Amenu, G. G., and P. Kumar, 2008: A model for hydraulic redistribution incorporating coupled soil-root moisture transport. Hydrol. Earth Syst. Sci., 12, 55-74, doi:10.5194/ hess-12-55-2008.

Arneth, A., J. Lloyd, H. Santruckova, M. Bird, S. Grigoryev, Y. N. Kalaschnikov, G. Gleixner, and E.-D. Schulze, 2002: Response of central Siberian Scots pine to soil water deficit and long-term trends in atmospheric $\mathrm{CO}_{2}$ concentration. Global Biogeochem. Cycles, 16, 1005, doi:10.1029/2000GB001374.

Atchley, A. L., and R. M. Maxwell, 2011: Influences of subsurface heterogeneity and vegetation cover on soil moisture, surface temperature and evapotranspiration at hillslope scales. Hydrogeol. J., 19, 289-305, doi:10.1007/s10040-010-0690-1.

Bastidas, L. A., H. V. Gupta, S. Sorooshian, W. J. Shuttleworth, and Z. L. Yang, 1999: Sensitivity analysis of a land surface scheme using multicriteria methods. J. Geophys. Res., 104, 19481-19490, doi:10.1029/1999JD900155.

Beringer, J., S. McIlwain, A. H. Lynch, F. S. Chapin III, and G. B. Bonan, 2002: The use of a reduced form model to assess the sensitivity of a land surface model to biotic surface parameters. Climate Dyn., 19, 455-466, doi:10.1007/ s00382-002-0237-9.

Bonan, G. B., P. J. Lawrence, K. W. Oleson, S. Levis, M. Jung, M. Reichstein, D. M. Lawrence, and S. C. Swenson, 2011: Improving canopy processes in the Community Land Model version 4 (CLM4) using global flux fields empirically inferred from FLUXNET data. J. Geophys. Res., 116, G02014, doi:10.1029/2010JG001593.

- K. W. Oleson, R. A. Fisher, G. Lasslop, and M. Reichstein, 2012: Reconciling leaf physiological traits and canopy flux data: Use of the TRY and FLUXNET databases in the Community Land Model version 4. J. Geophys. Res., 117, G02026, doi:10.1029/2011JG001913.

Campbell, G. S., and J. M. Norman, 1998: An Introduction to Environmental Biophysics. 2nd ed. Springer, $286 \mathrm{pp}$.

Chen, J. M., J. Liu, J. Cihlar, and M. L. Goulden, 1999: Daily canopy photosynthesis model through temporal and spatial scaling for remote sensing applications. Ecol. Modell., 124, 99-119, doi:10.1016/S0304-3800(99)00156-8.

Collatz, G. J., J. T. Ball, C. Grivet, and J. A. Berry, 1991: Physiological and environmental regulation of stomatal conductance, photosynthesis and transpiration: A model that includes a laminar boundary layer. Agric. For. Meteor., 54, 107-136, doi:10.1016/0168-1923(91)90002-8.

Condon, L. E., and R. M. Maxwell, 2014: Groundwater-fed irrigation impacts spatially distributed temporal scaling behavior of the natural system: A spatio-temporal framework for understanding water management impacts. Environ. Res. Lett., 9, 034009, doi:10.1088/1748-9326/9/3/034009.

Constantine, P. G., 2015: Active Subspaces: Emerging Ideas in Dimension Reduction for Parameter Studies. SIAM, 110 pp.

- M. Emory, J. Larsson, and G. Iaccarino, 2014: Exploiting active subspaces to quantify uncertainty in the numerical simulation of the HyShot II scramjet. J. Comput. Phys., 302, 1-20, doi:10.1016/j.jcp.2015.09.001.

Cook, R. D., 1998: Regression Graphics: Ideas for Studying Regressions through Graphics. John Wiley \& Sons, 349 pp. 
Damour, G., T. Simonneau, H. Cochard, and L. Urban, 2010: An overview of models of stomatal conductance at the leaf level. Plant Cell Environ., 33, 1419-1438, doi:10.1111/ j.1365-3040.2010.02181.x.

Drake, B. G., M. A. Gonzalez-Meler, and S. P. Long, 1997: More efficient plants: A consequence of rising atmospheric $\mathrm{CO}_{2}$ ? Annu. Rev. Plant Physiol. Plant Mol. Biol., 48, 609-639, doi:10.1146/annurev.arplant.48.1.609.

Farquhar, G. D., S. von Caemmerer, and J. A. Berry, 1980: A biochemical model of photosynthetic. Planta, 149, 78-90, doi:10.1007/BF00386231.

Ferguson, I. M., J. L. Jefferson, R. M. Maxwell, and S. J. Kollet, 2016: Effects of root water uptake formulation on simulated water and energy budgets at local and basin scales. Environ. Earth Sci., 75, 1-15, doi:10.1007/s12665-015-5041-z.

Field, C. B., R. B. Jackson, and H. A. Mooney, 1995: Stomatal responses to increased $\mathrm{CO} 2$ : Implications from the plant to global scale. Plant Cell Environ., 18, 1214-1225, doi:10.1111/ j.1365-3040.1995.tb00630.x.

Gilbert, J., J. Jefferson, P. G. Constantine, and R. Maxwell, 2016: Global spatial sensitivity to runoff of subsurface permeability. Adv. Water Resour., 92, 30-42, doi:10.1016/ j.advwatres.2016.03.020.

Göhler, M., J. Mai, and M. Cuntz, 2013: Use of eigendecomposition in a parameter sensitivity analysis of the Community Land Model. J. Geophys. Res. Biogeosci., 118, 904-921, doi:10.1002/ jgrg.20072.

Gou, S., 2014: Study of multi-scale plant-groundwater interactions. Ph.D. thesis, Texas A\&M University, 182 pp. [Available online at http://hdl.handle.net/1969.1/153271.]

Gu, L., S. G. Pallardy, K. Tu, B. E. Law, and S. D. Wullschleger, 2010: Reliable estimation of biochemical parameters from $\mathrm{C}_{3}$ leaf photosynthesis-intercellular carbon dioxide response curves. Plant Cell Environ., 33, 1852-1874, doi:10.1111/ j.1365-3040.2010.02192.x.

Henderson-Sellers, A., 1993: A factorial assessment of the sensitivity of the BATS land-surface parameterization scheme. J. Climate, 6, 227-247, doi:10.1175/1520-0442(1993)006<0227: AFAOTS $>2.0 . \mathrm{CO} ; 2$

Jarvis, P. G., 1976: The interpretation of the variations in leaf water potential and stomatal conductance found in canopies in the field. Philos. Trans. Roy. Soc. London, 273B, 593-610, doi:10.1098/rstb.1976.0035.

Jefferson, J. L., J. Gilbert, P. G. Constantine, and R. M. Maxwell, 2015: Active subspaces for sensitivity analysis and dimension reduction of an integrated hydrologic model. Comput. Geosci., 83, 127-138, doi:10.1016/j.cageo.2015.07.001.

Kattge, J., W. Knorr, T. Raddatz, and C. Wirth, 2009: Quantifying photosynthetic capacity and its relationship to leaf nitrogen content for global-scale terrestrial biosphere models. Global Change Biol., 15, 976-991, doi:10.1111/j.1365-2486.2008.01744.x.

Katul, G., S. Manzoni, S. Palmroth, and R. Oren, 2010: A stomatal optimization theory to describe the effects of atmospheric $\mathrm{CO}_{2}$ on leaf photosynthesis and transpiration. Ann. Bot., 105, 431-442, doi:10.1093/aob/mcp292.

Kollet, S. J., and R. M. Maxwell, 2008: Capturing the influence of groundwater dynamics on land surface processes using an integrated, distributed watershed model. Water Resour. Res., 44, W02402, doi:10.1029/2007WR006004.

Kosugi, Y., S. Takanashi, N. Matsuo, K. Tanaka, and H. Tanaka, 2006: Impact of leaf physiology on gas exchange in a Japanese evergreen broad-leaved forest. Agric. For. Meteor., 139, 182 199, doi:10.1016/j.agrformet.2006.06.009.
Kucharik, C. J., and Coauthors, 2000: Testing the performance of a Dynamic Global Ecosystem Model: Water balance, carbon balance, and vegetation structure. Global Biogeochem. Cycles, 14, 795-825, doi:10.1029/1999GB001138.

Lawrence, D. M., P. E. Thornton, K. W. Oleson, and G. B. Bonan, 2007: The partitioning of evapotranspiration into transpiration, soil evaporation, and canopy evaporation in a GCM: Impacts on land-atmosphere interaction. J. Hydrometeor., $\mathbf{8}$ 862-880, doi:10.1175/JHM596.1.

Leuning, R., F. M. Kelliher, D. G. G. de Pury, and E. D. Schulze, 1995: Leaf nitrogen, photosynthesis, conductance and transpiration: Scaling from leaves to canopies. Plant Cell Environ., 18, 1183-1200, doi:10.1111/j.1365-3040.1995.tb00628.x.

Li, J., and Coauthors, 2013: Assessing parameter importance of the Common Land Model based on qualitative and quantitative sensitivity analysis. Hydrol. Earth Syst. Sci., 17, 3279-3293, doi:10.5194/hess-17-3279-2013.

Liang, X., and J. Guo, 2003: Intercomparison of land-surface parameterization schemes: Sensitivity of surface energy and water fluxes to model parameters. J. Hydrol., 279, 182-209, doi:10.1016/S0022-1694(03)00168-9.

Liu, Y., H. V. Gupta, S. Sorooshian, L. A. Bastidas, and W. J. Shuttleworth, 2004: Exploring parameter sensitivities of the land surface using a locally coupled land-atmosphere model. J. Geophys. Res., 109, D21101, doi:10.1029/2004JD004730.

Lukaczyk, T. W., P. Constantine, F. Palacios, and J. J. Alonso, 2014: Active subspaces for shape optimization. 10th AIAA Multidisciplinary Design Optimization Conf., National Harbor, MD, AIAA, AIAA 2014-1171, doi:10.2514/6.2014-1171.

Mikkelson, K. M., R. M. Maxwell, I. Ferguson, J. D. Stednick, J. E. McCray, and J. O. Sharp, 2013: Mountain pine beetle infestation impacts: Modeling water and energy budgets at the hill-slope scale. Ecohydrology, 6, 64-72, doi:10.1002/eco.278.

Miller, G. R., X. Chen, Y. Rubin, S. Ma, and D. D. Baldocchi, 2010 Groundwater uptake by woody vegetation in a semiarid oak savanna. Water Resour. Res., 46, W10503, doi:10.1029/ 2009WR008902.

NASA, 2015: Global maps. Accessed 17 November 2015. [Available online at http://earthobservatory.nasa.gov/GlobalMaps/ view.php?d1=MOD13A2_M_NDVI.]

Oleson, K. W., and Coauthors, 2013: Technical description of version 4.5 of the Community Land Model (CLM). NCAR Tech. Note NCAR/TN-503+STR, 420 pp., doi:10.5065/ D6RR1W7M.

Osuna, J. L., D. D. Baldocchi, H. Kobayashi, and T. E. Dawson, 2015: Seasonal trends in photosynthesis and electron transport during the Mediterranean summer drought in leaves of deciduous oaks. Tree Physiol., 35, 485-500, doi:10.1093/treephys/tpv023.

Prihodko, L., S. Denning, N. P. Hanan, I. Baker, and K. Davis, 2008: Sensitivity, uncertainty and time dependence of parameters in a complex land surface model. Agric. For. Meteor., 148, 268-287, doi:10.1016/j.agrformet.2007.08.006.

Rosero, E., Z.-L. Yang, T. Wagener, L. E. Gulden, S. Yatheendradas, and G.-Y. Niu, 2010: Quantifying parameter sensitivity, interaction, and transferability in hydrologically enhanced versions of the Noah land surface model over transition zones during the warm season. J. Geophys. Res., 115 D03106, doi:10.1029/2009JD012035.

Schlaepfer, D. R., B. E. Ewers, B. N. Shuman, D. G. Williams, J. M. Frank, W. J. Massman, and W. K. Lauenroth, 2014: Terrestrial water fluxes dominated by transpiration: Comment. Ecosphere, 5, 61, doi:10.1890/ES13-00391.1. 
Sellers, P. J., and Coauthors, 1996: A revised land surface parameterization (SiB2) for atmospheric GCMs. Part I: Model formulation. J. Climate, 9, 676-705, doi:10.1175/ 1520-0442(1996)009<0676:ARLSPF >2.0.CO;2.

Sulis, M., P. Shrestha, M. Langensiepen, A. Schickling, C. Simmer, and S. J. Kollet, 2015: Evaluating the influence of plant-specific physiological parameterizations on the partitioning of land surface energy fluxes. J. Hydrometeor., 16, 517-533, doi:10.1175/JHM-D-14-0153.1.

Tanaka, K., Y. Kosugi, and A. Nakamura, 2002: Impact of leaf physiological characteristics on seasonal variation in $\mathrm{CO}_{2}$, latent and sensible heat exchanges over a tree plantation. Agric. For. Meteor., 114, 103-122, doi:10.1016/S0168-1923(02)00128-4.

Wilson, K. B., and D. D. Baldocchi, 2000: Seasonal and interannual variability of energy fluxes over a broadleaved temperate deciduous forest in North America. Agric. For. Meteor., 100, 1-18, doi:10.1016/S0168-1923(99)00088-X.
Woodrow, I. E., 1988: Enzymatic regulation of photosynthetic $\mathrm{CO}_{2}$ fixation in $\mathrm{C}_{3}$ plants. Annu. Rev. Plant Physiol. Plant Mol. Biol., 39, 533-594, doi:10.1146/annurev.pp.39.060188.002533.

Wullschleger, S. D., 1993: Biochemical limitations to carbon assimilation in $\mathrm{C}_{3}$ plants- $\mathrm{A}$ retrospective analysis of the $A / \mathrm{Ci}$ curves from 109 species. J. Exp. Bot., 44, 907-920, doi:10.1093/ $\mathrm{jxb} / 44.5 .907$.

$\mathrm{Xu}$, L., and D. D. Baldocchi, 2003: Seasonal trends in photosynthetic parameters and stomatal conductance of blue oak (Quercus douglasii) under prolonged summer drought and high temperature. Tree Physiol., 23, 865-877, doi:10.1093/ treephys/23.13.865.

Zhang, X., M. A. Friedl, and C. B. Schaaf, 2006: Global vegetation phenology from Moderate Resolution Imaging Spectroradiometer (MODIS): Evaluation of global patterns and comparison with in situ measurements. J. Geophys. Res., 111, G04017, doi:10.1029/2006JG000217. 